\title{
Etanercept Versus Monoclonal Antibodies in Axial Spondyloarthritis: Game Over?
}
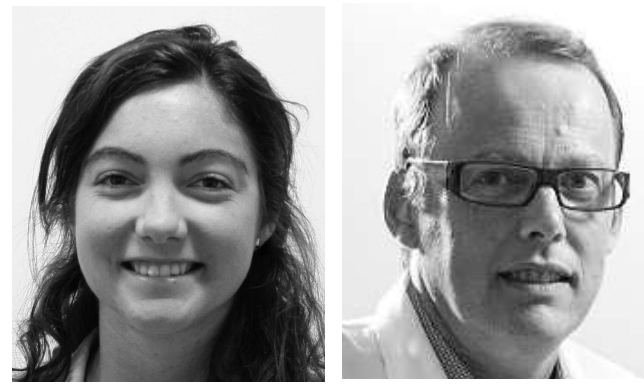

More than 10 years of experience with anti-tumor necrosis factor- $\alpha$ (TNF- $\alpha$ ) therapy in ankylosing spondylitis (AS) has brought us new therapeutic players. As respectively infliximab (IFX), etanercept (ETN), adalimumab, golimumab, and certolizumab were introduced, we were confronted with new modes of administration. However, regarding efficacy on axial and peripheral manifestations, all 5 actors seem somewhat equipotent. Also, IFX, ETN, adalimumab, and golimumab have already shown longterm efficacy after 2 to 8 years in established $\mathrm{AS}^{1,2,3,4}$. Nevertheless, treatment with TNF- $\alpha$ blocking agents such as adalimumab and ETN has shown similar high efficacy, with up to $54.5 \%$ ASAS40 (Assessment of Spondyloarthritis international Society $40 \%$ ) response in early disease ${ }^{5,6}$. In this issue of The Journal, Song, et al report results on the longterm efficacy of ETN in patients with early axial spondyloarthritis $(\mathrm{axSpA})^{7}$.

Efficacy of TNF- $\alpha$ blocking agents. Generally speaking, 2 types of TNF- $\alpha$ therapy are distinguished: ETN, a soluble TNF- $\alpha$ receptor antagonist, and monoclonal antibodies. All TNF blocking agents display similar short-term efficacy in

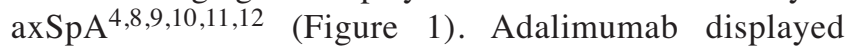
sustained clinical efficacy after 2 years of treatment with an ASAS40 response of $39.4 \%$ at Week 24 to an ASAS40 response in $50.6 \%$ after 2 years ${ }^{2,10}$. Also IFX maintained ASAS20 response of $84.8 \%$ after 8 years of treatment ${ }^{13}$. Similar results can be found in ETN and golimumab after 2 years ${ }^{3,4}$. However, all of these followup studies have been published in AS, generally comprising patients with longer disease duration and more progressive disease.

Song, et al provide the longterm data of the ESTHER trial with ETN over 3 years. Initially, AS and nonradiographic axSpA (nr-axSpA) with a disease duration of less than 5 years and active inflammation on magnetic resonance imaging (MRI) were treated with ETN or sulfasalazine (SSZ) during a 48-week period. ETN-treated patients responded better regarding MRI inflammation and clinical response than did the SSZ group ${ }^{14}$. Afterward, all patients were switched to ETN and displayed similar response rates in AS and nr-axSpA, provided that baseline characteristics were comparable ${ }^{6}$. Notably, the mean disease duration was 2.7 years, depicting early disease. Clinical response was consistently maintained over 1,2, and even 3 years in both groups with ASAS partial remission obtained in $43.9 \%$ of patients. In fact, no differences regarding response of objective markers such as MRI scores and C-reactive protein, or clinical disease activity markers such as Bath AS Disease Activity Index or AS Disease Activity Score, could be detected over time between AS and nr-axSpA. However, we must underline the high dropout rate of almost 50\% during this followup period. Therefore these results should be interpreted with caution.

Extraarticular manifestations. Many clinical trials and observational cohorts have shown some inferiority when it comes to the treatment of the extraarticular manifestations (EAM) in SpA. Regarding the treatment of acute anterior uveitis, monoclonal antibodies have proven effective. The effect of ETN, however, is less pronounced. The initial clinical trials in inflammatory bowel disease have shown no efficacy in treatment with ETN ${ }^{15,16}$.

On the other hand, in SpA-related skin disorders such as psoriasis, the receptor antagonist displays a dose-response relationship, with high dosage of the drug to suppress skin inflammation in a comparable degree to monoclonal antibodies. Psoriasis Area and Severity Index 75 could be achieved in only $26 \%$, possibly underlining the insufficient disease control with ETN in psoriatic arthritis ${ }^{17}$.

Unfortunately, no longterm ESTHER data regarding EAM are reported in this article. Therefore the longterm effect of ETN on these EAM in early disease remains to be determined.

Safety. Considering various registries across the globe, the overall risk of serious infections associated with anti-TNF is reassuring, especially in young patients and in compari-

See Good response with etanercept in axial SpA, page 2034

Personal non-commercial use only. The Journal of Rheumatology Copyright (c) 2014. All rights reserved. 


\section{ASAS40 response (week24)}

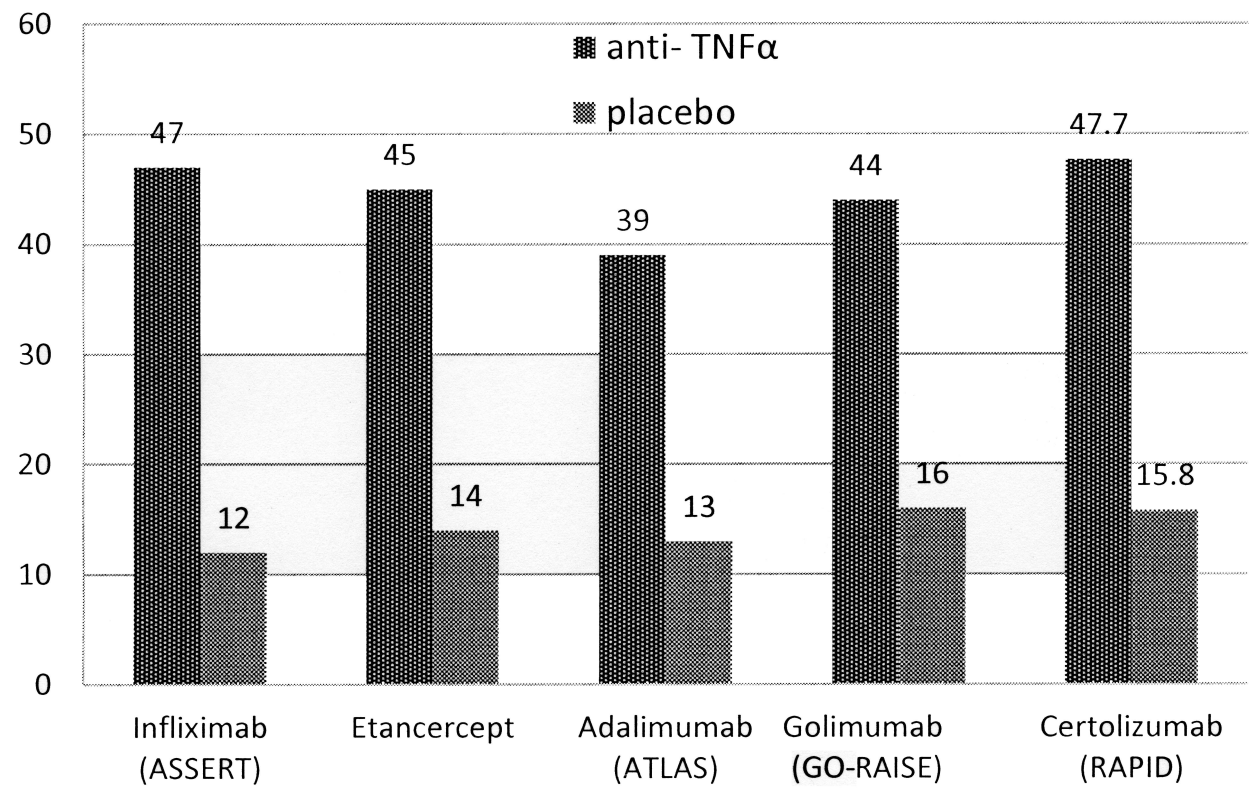

Figure 1. Clinical efficacy of anti-tumor necrosis factor (TNF)- $\alpha$ agents in ankylosing spondylitis $4,8,9,10,11,12$ ASAS: Assessment of Spondyloarthritis international Society (guidelines).

son to other nonbiologic disease-modifying antirheumatic drugs (DMARD). The British registry (BSRBR) presented adjusted hazard ratios declining from 1.8 in the first 6 months to 1.3 in the following months without clear differences across the 3 actors $^{18}$. The DREAM registry, however, introduced a more generous profile in favor of ETN to IFX and adalimumab, which presented a 2-fold higher risk of serious infections ${ }^{19}$. Similar findings were reported in the US Safety Assessment of Biologic Therapy registry ${ }^{20}$. Also, the risk of tuberculosis (TB) and opportunistic infections is remarkably higher in monoclonal antibodies in comparison to $\mathrm{ETN}^{21}$.

Overall, anti-TNF did not show an increased risk of solid malignancies or lymphoma, except for some contradictory reports of a slightly higher risk for non-melanoma skin cancer $^{22}$. The higher incidence of lymphoma is a known phenomenon in inflammatory diseases, especially rheumatoid arthritis. There are recent data from the BSRBR suggesting a beneficial effect of ETN on the occurrence of mortality and lymphoma in comparison to other DMARD and monoclonal antibodies, but this needs to be confirmed ${ }^{23}$

Occurrence of adverse events in 3 year followup of ETN in axSpa consisted mainly of mild upper respiratory tract infections. Only one case of a serious adverse event of sarcoidosis could possibly be linked to ETN therapy. No opportunistic infections, TB, or malignancies were observed. There is ample evidence from registries about the safety profiles of the biologicals regarding infections, malignancies, and overall safety over time, compared to the general population and other DMARD. This setting is more appropriate for the safety evaluation than the "long"-term followup of a small sample size in a clinical trial setting.

Structural damage. The evaluation of radiographic progression is usually performed by the modified Stokes AS spinal score (mSASS). It has been extensively evaluated and validated, despite its known limitations (inclusion of both erosive and osteoproliferative features, and the neglect of the thoracic spine). Initially, anti-TNF failed to deliver the anticipated effect on radiographic progression by reduction of MRI inflammation. However, this was mainly due to the quality of the comparative cohort, the low sensitivity of mSASS, and the inadequate followup period. Haroon, et al could demonstrate a $50 \%$ reduction in progression as a result of anti-TNF therapy comparing radiographs more than 1.5 years apart ${ }^{24}$. Also, several authors have provided data in which patients treated with anti-TNF were followed prospectively for 8 years ${ }^{25,26}$. Considering Baraliakos, et $a l^{25}$, a difference in progression rate was seen only in the second half of the observation. Strikingly, both groups in both studies exhibited radiographic progression despite "optimal" therapy. The latter findings and the discovery that up to $64 \%$ of patients in Ankylosing Spondylitis Disease Activity Score inactive disease and $72 \%$ of patients in ASAS partial remission show active inflammation on MRI of the sacroiliac joints or spine under ETN treatment in the ESTHER trial by Song, et al, support the presence of silent disease activity in the absence of overt clinical signs. The

Personal non-commercial use only. The Journal of Rheumatology Copyright @ 2014 . All rights reserved 
effect of this residual disease activity on the longterm structural progression therefore remains to be determined.

TNF- $\alpha$ blocking agents, and most recently ETN, have displayed similar efficacy in short and longterm followup studies in early disease. They do, however, show some discrepancies in the management of extraarticular manifestations and safety profiles.

Regarding the choice of anti-TNF- $\alpha$, an individual assessment of the patient should be made. Age, comorbidities, concomitant medication, and overall immunosuppression, extraarticular manifestations, risk of infection, living conditions, and even regional aspects (for example, exposure risk to $\mathrm{TB}$ ) need to be taken into account regarding the choice of anti-TNF- $\alpha$ for the individual patient. The favorable safety profile of ETN may be crucial in some vulnerable patients, whereas the suppression of a recurrent uveitis may be the main clinical problem in others.

As demonstrated by Song, et al, clinical remission may not reflect MRI remission, which highlights the importance of MRI, also in followup. However, additional data regarding the differential evolution of MRI-positive and MRI-negative patients are needed.

\section{GAËLLE VARKAS, MD; DIRK ELEWAUT, $\mathrm{MD}, \mathrm{PhD}$,} Department of Rheumatology University of Ghent, Ghent, Belgium.

Address correspondence to Dr. Elewaut, University of Ghent, Rheumatology, De Pintelaan 185, Ghent 9000 Belgium;

E-mail: dirk.elewaut@ugent.be

\section{REFERENCES}

1. Braun J, Baraliakos X, Listing J, Fritz C, Alten R, Burmester G, et al. Persistent clinical efficacy and safety of anti-tumour necrosis factor alpha therapy with infliximab in patients with ankylosing spondylitis over 5 years: evidence for different types of response. Ann Rheum Dis 2008;67:340-5.

2. van der Heijde D, Schiff MH, Sieper J, Kivitz AJ, Wong RL, Kupper $\mathrm{H}$, et al. Adalimumab effectiveness for the treatment of ankylosing spondylitis is maintained for up to 2 years: long-term results from the ATLAS trial. Ann Rheum Dis 2009;68:922-9.

3. Dijkmans B, Emery P, Hakala M, Leirisalo-Repo M, Mola EM, Paolozzi L, et al. Etanercept in the longterm treatment of patients with ankylosing spondylitis. J Rheumatol 2009;36:1256-64.

4. Braun J, Deodhar A, Inman RD, van der Heijde D, Mack M, Xu S, et al. Golimumab administered subcutaneously every 4 weeks in ankylosing spondylitis: 104-week results of the GO-RAISE study. Ann Rheum Dis 2012;71:661-7.

5. Haibel H, Rudwaleit M, Listing J, Heldmann F, Wong RL, Kupper $\mathrm{H}$, et al. Efficacy of adalimumab in the treatment of axial spondylarthritis without radiographically defined sacroiliitis: results of a twelve-week randomized, double-blind, placebo-controlled trial followed by an open-label extension up to week fifty-two. Arthritis Rheum 2008;58:1981-91.

6. Song IH, Weiss A, Hermann KG, Haibel H, Althoff CE, Poddubnyy $\mathrm{D}$, et al. Similar response rates in patients with ankylosing spondylitis and non-radiographic axial spondyloarthritis after 1 year of treatment with etanercept: results from the ESTHER trial. Ann Rheum Dis 2013;72:823-5.
7. Song IH, Hermann KG, Haibel H, Althoff CE, Poddubnyy D, Listing J. Spondyloarthritis after 3 years of continuous treatment with etanercept: longterm data of the ESTHER trial. J Rheumatol 2014;41:2034-40.

8. Landewé R, Braun J, Deodhar A, Dougados M, Maksymowych WP, Mease PJ, et al. Efficacy of certolizumab pegol on signs and symptoms of axial spondyloarthritis including ankylosing spondylitis: 24-week results of a double-blind randomised placebo-controlled Phase 3 study. Ann Rheum Dis 2014;73:39-47.

9. Davis JC Jr., Van Der Heijde D, Braun J, Dougados M, Cush J, Clegg DO, et al. Recombinant human tumor necrosis factor receptor (etanercept) for treating ankylosing spondylitis: a randomized, controlled trial. Arthritis Rheum. 2003;48:3230-6.

10. van der Heijde D, Kivitz A, Schiff MH, Sieper J, Dijkmans BA, Braun J, et al. Efficacy and safety of adalimumab in patients with ankylosing spondylitis: results of a multicenter, randomized, double-blind, placebo-controlled trial. Arthritis Rheum 2006;54:2136-46.

11. van der Heijde D, Dijkmans B, Geusens P, Sieper J, DeWoody K, Williamson P, et al. Efficacy and safety of infliximab in patients with ankylosing spondylitis: results of a randomized, placebo-controlled trial (ASSERT). Arthritis Rheum 2005; 52:582-91

12. Braun J, Brandt J, Listing J, Zink A, Alten R, Golder W, et al. Treatment of active ankylosing spondylitis with infliximab: a randomised controlled multicentre trial. Lancet 2002;359:1187-93.

13. Baraliakos X, Listing J, Fritz C, Haibel H, Alten R, Burmester GR, et al. Persistent clinical efficacy and safety of infliximab in ankylosing spondylitis after 8 years - early clinical response predicts long-term outcome. Rheumatology 2011;50:1690-9.

14. Song IH, Hermann K, Haibel H, Althoff CE, Listing J, Burmester $\mathrm{G}$, et al. Effects of etanercept versus sulfasalazine in early axial spondyloarthritis on active inflammatory lesions as detected by whole-body MRI (ESTHER): a 48-week randomised controlled trial. Ann Rheum Dis 2011;70:590-6.

15. Sandborn WJ, Hanauer SB, Katz S, Safdi M, Wolf DG, Baerg RD, et al. Etanercept for active Crohn's disease: a randomized, double-blind, placebo-controlled trial. Gastroenterology 2001;121:1088-94.

16. Van Praet L, Van den Bosch FE, Jacques P, Carron P, Jans L, Colman R, et al. Microscopic gut inflammation in axial spondyloarthritis: a multiparametric predictive model. Ann Rheum Dis 2013;72:414-7.

17. Mease PJ. Tumour necrosis factor (TNF) in psoriatic arthritis: pathophysiology and treatment with TNF inhibitors. Ann Rheum Dis 2002;61:298-304.

18. Galloway JB, Hyrich KL, Mercer LK, Dixon WG, Fu B, Ustianowski AP, et al. Anti-TNF therapy is associated with an increased risk of serious infections in patients with rheumatoid arthritis especially in the first 6 months of treatment: updated results from the British Society for Rheumatology Biologics Register with special emphasis on risks in the elderly. Rheumatology 2011;50:124-31

19. van Dartel SA, Fransen J, Kievit W, Flendrie M, den Broeder AA, Visser H, et al. Difference in the risk of serious infections in patients with rheumatoid arthritis treated with adalimumab, infliximab and etanercept: results from the Dutch Rheumatoid Arthritis Monitoring (DREAM) registry. Ann Rheum Dis 2013;72:895-900.

20. Baddley JW, Winthrop KL, Chen L, Liu L, Grijalva CG, Delzell E, et al. Non-viral opportunistic infections in new users of tumour necrosis factor inhibitor therapy: results of the SAfety Assessment of Biologic ThERapy (SABER) Study. Ann Rheum Dis 2013 Jul 13 (E-pub ahead of print).

21. Salmon-Ceron D, Tubach F, Lortholary O, Chosidow O, Bretagne

Personal non-commercial use only. The Journal of Rheumatology Copyright @ ${ }^{2014}$. All rights reserved. 
$\mathrm{S}$, Nicolas N, et al. Drug-specific risk of non-tuberculosis opportunistic infections in patients receiving anti-TNF therapy reported to the 3-year prospective French RATIO registry. Ann Rheum Dis 2011;70:616-23.

22. Haynes K, Beukelman T, Curtis JR, Newcomb C, Herrinton LJ, Graham DJ, et al. Tumor necrosis factor alpha inhibitor therapy and cancer risk in chronic immune-mediated diseases. Arthritis Rheum 2013;65:48-58.

23. Mariette X, Tubach F, Bagheri H, Bardet M, Berthelot JM, Gaudin $\mathrm{P}$, et al. Lymphoma in patients treated with anti-TNF: results of the 3-year prospective French RATIO registry. Ann Rheum Dis 2010;69:400-8.

24. Haroon N, Inman RD, Learch TJ, Weisman MH, Lee M, Rahbar $\mathrm{MH}$, et al. The impact of tumor necrosis factor alpha inhibitors on radiographic progression in ankylosing spondylitis. Arthritis Rheum 2013;65:2645-54.

25. Baraliakos X, Haibel H, Listing J, Sieper J, Braun J. Continuous long-term anti-TNF therapy does not lead to an increase in the rate of new bone formation over 8 years in patients with ankylosing spondylitis. Ann Rheum Dis 2014;73:710-5.

26. Bennett AN, McGonagle D, O'Connor P, Hensor EM, Sivera F, Coates LC, et al. Severity of baseline magnetic resonance imaging-evident sacroiliitis and HLA-B27 status in early inflammatory back pain predict radiographically evident ankylosing spondylitis at eight years. Arthritis Rheum 2008;58:3413-8.

J Rheumatol 2014;41:1899-902; doi:10.3899/jrheum.140866 